\title{
The Evaluation of Whole-Body Vibration Level in Hand-Held Pneumatic TOOls (Rock Drill) By "PNEuRop Cagi TeSt Code" Method
}

\author{
Farhad Forouhar Majd ${ }^{1.2}$, Parvin Nassiri ${ }^{2}$ \\ ${ }^{1}$ Dept. of Occupational Health, School of Public Health, Isfahan University of Medical Sciences and Health Services, Hezar \\ Jerib Ave, Isfahan, Iran, forouhar@hlth.mui.ac.ir \\ ${ }^{2}$ Dept. of Occupational Health, School of Public Health and Institute of Public Health Research, Tehran University of Medical \\ Sciences, Enghelab Ave, Tehran, Iran, nassiri@sina.tums.ac.ir
}

\section{INTRODUCTION}

The evaluation of whole-body vibration in hand-held pneumatic tools (Rock drills) used in lashotor stone mines in Isfahan by the method of PNEUROP CAGI TEST CODE $[1,2]$ shows the methods which are provided how to use of construction equipment in stone mines under work circumstances.

All hand-held machines transmit vibrations to our hands while we are working with them [3]. Vibrations consist of a reciprocal motion in handles which arises when a number of forces with varying directions and magnitude influence the machine and set it in motion. Work with intensely vibrating machines for a long period of time may give rise to different types of injury. Main types of injuries likely to occur are largely vascular injury, nerve injury, skeletal injury and joint injuries. Perhaps, the most famous injury is vibration induced white fingers or Raynaud's phenomena [4].

This method is designed to evaluate noise and vibration propagated by the hand-held pneumatic tools [5]. Rock drills are categorized as the major sources of noise and vibration by the federal noise control Act of $1972[5,6]$.

The paper demonstrates vibration values generated by rock drill in three directions of $\mathrm{X}, \mathrm{Y}$ and $\mathrm{Z}$ axes and of course a comparison of three vital indices for workers while working with equipment with the standard graphs related to the above specify test method.

\section{METHOD}

\subsection{Physical quantities}

It has been found that measurement of vibrations on hand-held tools is far more difficult than we originally envisaged. When measuring vibrations, it is very difficult to decide subjectively whether or not the results of our measurements are reasonable. A motion can be described in terms of displacement, velocity or acceleration [7]. Between these three units, displacement is the most obvious unit for engineer and the unit of acceleration is particular useful in making human vibration measurements $[8,9]$.

\subsection{Whole-body indices}

This paper focuses on measuring and predicting of created vibrations as whole-body indices in a rock drill used in stone mines by $\mathrm{B} \& \mathrm{~K}$ vibration meter 2512 model. In order to evaluate them we had to locate the whole-body accelerator on the ground where the operator was standing and processing his work [10]. The indices include Reduced Comport (RC), Fatigue Decreased Proficiency (FDP), and Exposure limit (EL) for a frequency response of $1-80 \mathrm{~Hz}$.

\section{RESULTS}

As can be seen in table 1, obtained conclusions have been shown considerable values of vibration acceleration in $\mathrm{Z}, \mathrm{X}$ and $\mathrm{Y}$ axes for exposure limit and fatigue decreased proficiency respectively. All values are considered for a 5 hour time of exposure.

Table 1. Exposure levels of whole-body transmitted vibrations from a rock drill in $X, Y$, and $Z$ axes.

\begin{tabular}{|c|c|c|c|c|}
\hline $\begin{array}{c}\text { Vibration } \\
\text { levels }\end{array}$ & $\begin{array}{c}\mathrm{X}, \mathrm{Y} \\
(\mathrm{dB})\end{array}$ & $\mathrm{X}, \mathrm{Y}\left(\mathrm{m} / \mathrm{s}^{2}\right)$ & $\mathrm{Z}(\mathrm{dB})$ & $\mathrm{Z}\left(\mathrm{m} / \mathrm{s}^{2}\right)$ \\
\hline \multicolumn{5}{|c|}{ Exposure Limit } \\
\hline Peak & 110 & 0.31 & 142 & 12.5 \\
\hline Leq & 101 & 0.11 & 130 & 3.2 \\
\hline rms & 103 & 0.14 & 127 & 2.2 \\
\hline \multicolumn{5}{|c|}{ Fatigue Decreased Proficiency } \\
\hline Peak & 123 & 1.4 & 137 & 7 \\
\hline Leq & 101 & 0.25 & 121 & 1.1 \\
\hline rms & 112 & 0.39 & 125 & 1.77 \\
\hline
\end{tabular}

This is clear from figure 1 that the emitted vibrations from rock drill are strongly issued in $Z$ direction of wholebody vibration axes with a peak of $12.5 \mathrm{~m} / \mathrm{s}^{2}$ for E.L.

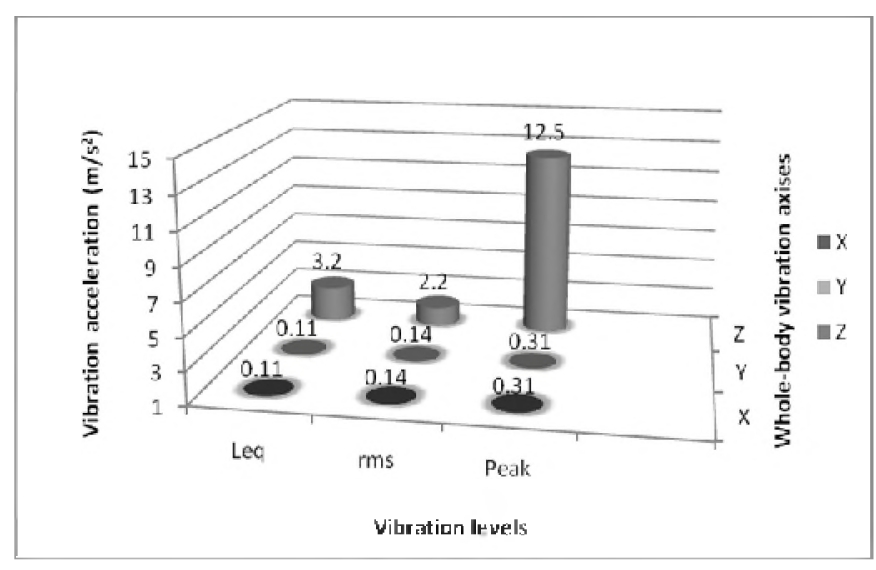

Fig. 1. Evaluated measures of Exposure Limit index of wholebody vibration acceleration produced by a rock drill used in stone mine in three different axes $(X, \dot{Y}, Z)$ for leq, rms and peak vibration levels. 
The obtained results for fatigue decreased proficiency index demonstrate a peak of $7 \mathrm{~m} / \mathrm{s}^{2}$ acceleration in $Z$ direction compared to acceleration values of other vibration axes.

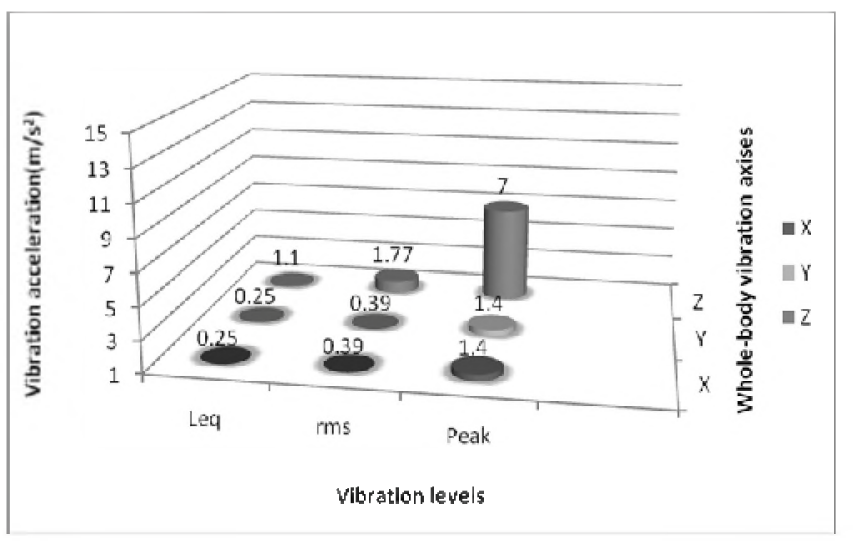

Fig. 2. Evaluated measures of Fatigue Decreased Proficiency index of whole-body vibration acceleration produced by a rock drill used in stone mine in three different axes $(X, Y, Z)$ for leq, rms and peak vibration levels.

The given values in table 2 are extracted from the ISO 2631,1985 graphs to describe permissible exposure levels of whole-body vibrations in low frequencies of a hand-held pneumatic tool [11].

We have concluded that the operator of rock drill should work only for a period of 1.5 hour per day when receiving all band of frequencies from 1 to $80 \mathrm{~Hz}$, otherwise we should protect him against vibration low frequencies.

The situation for fatigue decreased proficiency index is different and more limited than exposure limit index. In the table, the maximum permitted period of exposure to vibration is $30 \mathrm{~min}$ in a day. In other words, the FDP index says that operators should be protected against $1-30 \mathrm{~Hz}$ frequencies so that they are able to work for a long time with the rock drill.

Table 2. Allowable exposure time to rock drill whole-body vibration.

\begin{tabular}{|c|c|c|}
\hline Criteria & $\begin{array}{c}\text { Allowable } \\
\text { exposure time(hr) }\end{array}$ & Frequency rate(Hz) \\
\hline \multirow{4}{*}{\begin{tabular}{c} 
Exposure Limit \\
\cline { 2 - 3 }
\end{tabular}} & 8 & $25-80$ \\
\cline { 2 - 3 } & 5 & $18-80$ \\
\cline { 2 - 3 } & 2.5 & $15-80$ \\
\hline \multirow{3}{*}{$\begin{array}{c}\text { Fatigue Decreased } \\
\text { Proficiency }\end{array}$} & 1.5 & $11-80$ \\
\cline { 2 - 3 } & 8 & $1-80$ \\
\cline { 2 - 3 } & 5 & $40-80$ \\
\cline { 2 - 3 } & 2.5 & $30-80$ \\
\cline { 2 - 3 } & 1 & $16-80$ \\
\cline { 2 - 3 } & 0.5 & $11-80$ \\
\hline
\end{tabular}

\section{DISCUSSION}

Although we were faced to high measures of vibrations in different axes, but the most important of index in comparison with its recommended limits can be exposure limit, because it is a better weighted index for human vibration in workplaces [12]. Reduced comport Index is not also recommended for occupational and industrial jobs because of having more limitations.

With regarding to the above results the whole-body vibration frequencies from the specified rock drill and in low frequencies can be considered as a hazardous vibration source for human body especially for circulatory system, nerves and skeleton. We must pay attention to this subject that many of these workers prefer to do their duties while sitting on the handles of drill because of long period of time for drilling.

However, reduction of vibrations usually means that a thorough analysis of dynamic forces in the machine and process must be performed. This force analysis is followed by a study in different mass spring systems. Acceleration can be reduced by decreasing the force of excitation or increasing the effective mass. Acceleration can also be reduced through attenuation via a mass spring system $[13,14]$

In each case, reduction of emitted vibration can influence the vibration induced noise depending on vibration frequencies and therefore one of the best approach of control noise and vibration of a handle tool is vibrating surface elimination through:

- $\quad$ increasing the mass of drill body

- $\quad$ isolating the outer shell of motor

- balancing power transmission system

\section{REFERENCES}

[1] Handbook of noise control Chap 13-construction equipment M.C GrawHill - Book company, Harris .C 1973.

[2] Ergonomic tools in our time, Atlas Copco tools, 1988.

[3] Handbook of human vibration, M.J Griffin, 1990.

[4] Industrial health, M Takamatsu, Journal, 1982.

[5] Test code for the measurement of sound from pneumatic equipment $A N S I, 1971$

[6] Surface rock drills, Atlas Copco, 1991

[7] Handbook of noise and vibration control, Malcolm J. Crocker, 2007.

[8] Handbook of noise and vibration control, Antony Barber, 1992.

[9] Noise control foundation, $L E P O R-M, 1983$

[10] Sound and vibration, vol. 5. Page 4, Anonymous, 1991.

[11] Sound and vibration, vol. 10, page 6-33, Purcell, 1976.

[12] Test - site measurement of maximum noise emitted by engine powered equipment, $A S A, 3,1975$.

[13] Measurement of airborne noise emitted by construction equipment intended for outdoor use, ISO, 1976.

[14] Method for designation of sound power emitted by machinery and equipment by machinery and equipment, $A S A, 5,1976$ ANSI, 1976 